\title{
Hipomielinização em cães Weimaraner: relato de caso
}

\author{
[Hypomielination in Weimaraner dogs: case report] \\ A.M. Viott ${ }^{1}$, R.A. Fighera ${ }^{1}$, G.D. Kommers ${ }^{2}$, A.T. Ramos ${ }^{1}$, P. Maiorka ${ }^{3}$, D.L. Graça ${ }^{2 *}$ \\ ${ }^{1}$ Aluno de pós-graduação - UFSM - Santa Maria, RS \\ ${ }^{2}$ Universidade Federal de Santa Maria \\ Faixa do Camobi, km 9 \\ 97105-900 - Santa Maria, RS \\ ${ }^{3}$ Faculdade de Medicina Veterinária e Zootecnia - USP - São Paulo, SP
}

\begin{abstract}
RESUMO
Três cães, fêmeas, da raça Weimaraner apresentaram tremores corporais rítmicos generalizados a partir da primeira semana de vida. Outros dois cães, machos, da mesma ninhada não apresentaram alterações. Uma fêmea com quatro semanas de idade foi submetida à eutanásia e necropsiada. Macroscopicamente, observou-se no encéfalo pouca demarcação da substância branca em relação à cinzenta. Histologicamente havia acentuada vacuolização de toda a substância branca subcortical. A mielinização no sistema nervoso periférico estava normal. Os sinais clínicos, a idade de ocorrência e as lesões histológicas são compatíveis com a hipomielinogênese congênita descrita em cães.
\end{abstract}

Palavras-chave: cão, neuropatologia, hipomielinização, tremores

\begin{abstract}
Three female Weimaraner pups had generalized and rhythmic body tremors since the first week of age. The remaining two male littermates were unaffected. One 4-week-old female was euthanatized and necropsied. On gross examination, poor demarcation between the gray and white matter was observed. Microscopically, there was severe hypomyelination of the brain compatible with congenital hypomyelinogenesis reported in dogs.
\end{abstract}

Keywords: dog, neuropathology, hypomielination, trembler

\section{INTRODUÇÃO}

A hipomielinização é uma anomalia congênita relativamente comum em grandes animais, mas poucos casos são descritos em cães (Palmer et al., 1987). Há relatos desse distúrbio nas raças Dálmata, Springer Spaniels, Samoieda, Weimaraner (Konergay et al., 1987; Nadon et al., 1990), Montanhês de Berna e em cães sem raça definida (Palmer et al., 1987). Os animais afetados apresentam tremores generalizados a partir da primeira semana de vida (Summers et al., 1995). Sinais clínicos como dismetria e dificuldade de manter-se em estação também são relatados (Kornegay et al., 1987; Wagner et al., 1997). Sugere-se uma base hereditária na maioria dos casos de hipomielinogênese em cães (Nadon et al., 1990; Palmer et al., 1987). A lesão é observada apenas no sistema nervoso central (SNC) (Kornegay et al., 1987).

Neste trabalho descrevem-se os sinais clínicos observados em três cadelas Weimaraner, com quatro semanas de idade, e as alterações histológicas observadas em uma delas.

Recebido em 18 de novembro de 2005

Aceito em 4 de abril de 2007

*Autor para correspondência (corresponding author)

E-mail: dlgraça@smail.ufsm.br 


\section{CASUÍSTICA}

Em uma ninhada de cinco filhotes de cães Weimaraner, três fêmeas apresentaram tremores corporais generalizados a partir da primeira semana de vida. Dois machos não apresentaram alterações clínicas. Os tremores eram rítmicos acentuando-se quando os filhotes eram estimulados e diminuindo ou desaparecendo quando estavam em repouso ou dormindo. Ao caminhar, as cadelas apresentavam dismetria, mais acentuada nos membros posteriores, tornando o andar semelhante a "pulos de coelho".

Uma fêmea de quatro semanas de idade com pústulas na região abdominal ventral, foi submetida à eutanásia para a confirmação da suspeita clínica de cinomose. Na necropsia, não foram observadas alterações macroscópicas com exceção de pouca demarcação da substância branca em relação à cinzenta na superfície de corte do encéfalo. Na histologia, a substância branca subcortical apresentava acentuada vacuolização (Fig. 1), que também era vista de forma discreta e multifocal na substância branca do cerebelo, medula oblonga e pedúnculos cerebelares. A mielinização dos nervos cranianos mostrou-se sem alterações, contrastando com a hipomielinização do encéfalo (Fig. 2). Pelo luxol fast-blue observou-se que a maioria dos axônios do córtex cerebral achavam-se finamente mielinizados ou não-mielinizados, o mesmo ocorrendo nos pedúnculos cerebelares e na medula oblonga. O exame de imunofluorescência para cinomose foi negativo.

Nos cortes semi-finos corados pelo azul de metileno, poucos axônios possuíam bainha de mielina discerníveis (Fig. 3). Na ultraestrutura foram observados axônios finos e pouco mielinizados. As lamelas de mielina não eram compactadas (Fig. 4), e os axônios com mesmo diâmetro tinham bainhas de espessuras diferentes.

Informações adicionais, fornecidas pelo proprietário, reportam que esse foi o primeiro cruzamento entre os pais, e que as ninhadas anteriores dessa cadela foram normais. As outras duas fêmeas afetadas apresentaram melhora clínica progressiva, entretanto, uma foi caudectomizada devido aos traumatismos caudais freqüentes. Com um ano de idade ainda apresentavam tremores e incoordenação discretos.

\section{DISCUSSÃO}

O diagnóstico de hipomielinização baseou-se na semelhança dos sinais clínicos, idade e alterações macro e microscópicas, com casos descritos na literatura. Os sinais clínicos iniciaram-se na primeira semana de vida, confirmando descrições anteriores que citaram que os sinais clínicos se evidenciam entre a primeira e terceira semanas (Kornegay et al., 1987). Os tremores geralmente envolvem a cabeça, tronco e membros e a intensidade varia entre os animais de uma mesma ninhada.

Além do comprometimento da locomoção, os tremores musculares constantes interferem na capacidade de sucção do leite, acarretando baixo desenvolvimento corporal e, em casos extremos, morte por inanição. A ocorrência de natimortos, descrita em alguns casos (Wagner et al., 1997), não foi observada.

A macroscopia do encéfalo revelou pouca demarcação entre as substâncias branca e cinzenta, o que já foi observado por outros autores em secções do encéfalo e medula espinhal (Kornegay et al., 1987). Esse achado não é constante, pois, na maioria dos casos, o encéfalo não apresenta alterações macroscópicas (Summers et al., 1995). Entretanto, essa observação pode auxiliar na suspeita diagnóstica de hipomielinização.

As lesões observadas pela coloração de rotina vacuolização da substância branca - não foram suficientes para o diagnóstico, mas pelo luxol fastblue pôde-se verificar a deficiente mielinização. Kornegay et al. (1987) observaram graus variáveis de hipomielinização na medula espinhal e encéfalo, assim como diminuição no número de oligodendrócitos e/ou oligodendrócitos imaturos (gliogênese retardada). Espessamento da pia-máter, gliose e astrocitose já foram citados em Weimaraners e nos Springer Spaniels (Palmer et al., 1987) com hipomielinogênese. Houve marcada diferença na mielinização do encéfalo quando comparada ao sistema nervoso periférico (SNP). Isso pode ser explicado pelo fato do SNP ser mielinizado pelas células de Schwann e não por oligodendrócitos (Summers et al., 1995). 


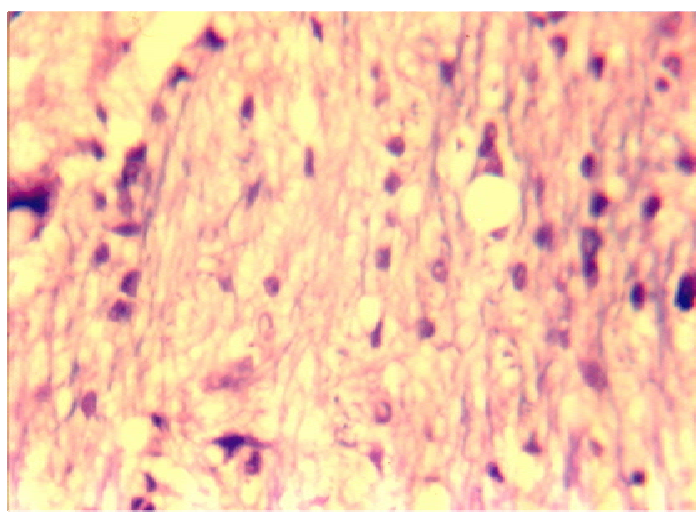

Figura 1. Cadela, quatro semanas de idade, encéfalo, substância branca subcortical. Observar a vacuolização acentuada. HE (40x).

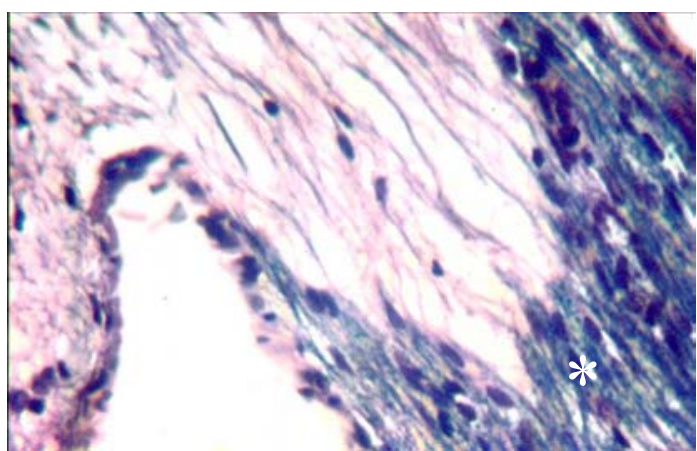

Figura 2. Cadela, quatro semanas de idade, ponte. Observar a hipomielinização acentuada da substância branca, contrastando com a mielinização normal de um nervo craniano (asterisco). Luxol fast-blue (40x).

O estudo ultraestrural de casos de hipomielinização revela axônios recobertos por bainhas de mielina finas, irregulares ou ausentes. Os oligodendrócitos podem estar em número normal ou reduzido. Muitos oligodendrócitos contêm vacúolos citoplasmáticos, que podem estar vazios ou repletos de gotas lipídicas e, ocasionalmente, o retículo endoplasmático rugoso está acentuadamente dilatado. As projeções citoplasmáticas dos oligodendrócitos são ausentes ou diminuídas e, quando ocorrem, não há uma compactação eficiente da mielina (Griffiths et al., 1981) semelhante ao que foi observado neste caso.

A importância da descrição deste caso deve-se à ocorrência infreqüente dessa condição, o que

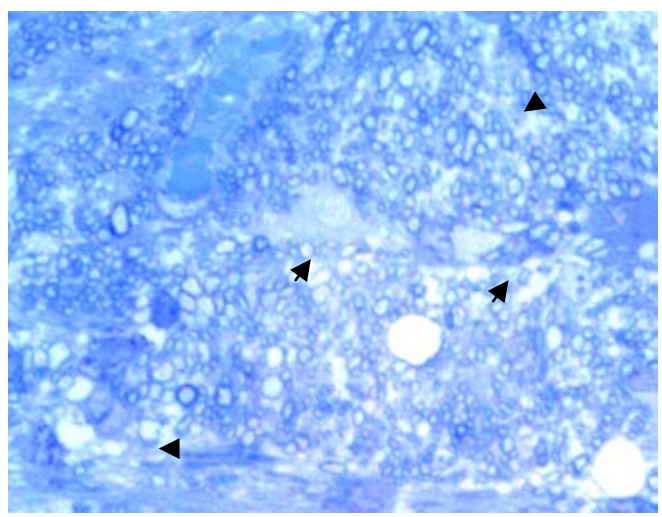

Figura 3. Cadela com quatro semanas de idade. Corte semi-fino da substância branca da ponte. As bainhas de mielina de muitos axônios não são discerníveis (setas). Axônios do mesmo tamanho possuem bainhas de espessuras diferentes (cabeças de seta). (Azul de metileno 10x).

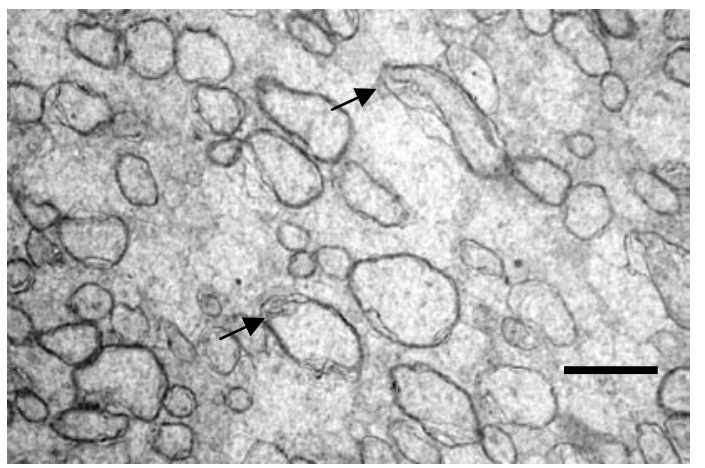

Figura 4. Fotomicrografia eletrônica da substância branca da ponte. Os axônios possuem bainhas de mielina finas e mal compactadas (setas). Barra: 1.02 micrômetros.

vem a fornecer dados que colaborem na identificação e diagnóstico de uma doença congênita que acomete cães de várias raças.

\section{REFERÊNCIAS BIBLIOGRÁFICAS}

GRIFFITHS, I.R.; DUNCAN, I.D.; McCULLOCH, M. et al. Shaking pups: a disorder of central myelination in the Spaniel dog. J. Neuro Sci., v.50, p.423-433, 1981.

KORNEGAY, J.N.; GOODWIN, M.A.; SPYRIDAKIS, L.K. Hypomyelination in Weimaraner dogs. Acta Neuropathol., v.72, p.394-401, 1987. 
NADON, N.L.; DUNCAN, I.D.; HUDSON, L.D. A point mutation in the proteolipid protein of the "shaking pup" interrupts oligodendrocyte development. Development, v.110, p.529-537, 1990.

PALMER, A.C.; BLAKEMORE, W.F.; WALLACE, M.E. et al. Recognition of "trembler", a hypomyelinating condition in the
Bernese mountain dog. Vet. Rec., v.120, p.609$612,1987$.

SUMMERS, B.A.; CUMMINGS, J.F.; LAHUNTA, A. (Eds). Veterinary neuropathology. Missouri: Mosby, 1995. 527p.

WAGNER, S.O.; PODELL, M.; FENNER, W.R. Generalized tremors in dogs: 24 cases. J. Am. Vet. Med. Assoc., v.211, p.731-735, 1997. 